\title{
Presença do Gênero Feminino entre os Discentes dos Programas de Pós-Graduação de Ciências Contábeis no Brasil
}

\section{Resumo}

Objetivo: apesar de existirem movimentos em direção à igualdade de gêneros quanto ao acesso à educação e às oportunidades no mercado de trabalho, a escassa presença da mulher em profissões que no passado eram, predominantemente, masculinas ainda pode persistir. Assim, este estudo objetiva verificar a presença do gênero feminino entre os discentes dos programas de pós-graduação em Ciências Contábeis do Brasil, no período de 2010 a 2016.

Método: na Plataforma Sucupira, foram selecionados os 26 cursos de mestrado acadêmico, os 5 de mestrado profissional e os 13 de doutorado em Ciências Contábeis credenciados pela Coordenação de Aperfeiçoamento de Pessoal de Nível Superior (CAPES), e com dados disponíveis para a pesquisa até 2016. Nesses, identificou-se um total de 3.013 discentes ingressantes, 2.058 de mestrado acadêmico, 530 de mestrado profissional e 451 de doutorado.

Resultados: os resultados da pesquisa indicam que o número de discentes do gênero feminino ingressantes nos programas de pós-graduação em Ciências Contábeis no Brasil são inferiores ao de discentes do gênero masculino, no período analisado, com visíveis diferenças regionais.

Contribuições: conclui-se que a presença do gênero feminino entre os discentes dos programas pesquisados tem evoluído, mas ainda há um longo caminho a ser percorrido para alcançar a igualdade de gêneros, o que é especialmente relevante se for considerado que isso pode se refletir em posteriores oportunidades de trabalho, uma lacuna de pesquisa a ser investigada.

Palavras-chave: Gênero feminino. Programas de PósGraduação. Ciências Contábeis.

\section{Daniele Cristina Bernd \\ Doutoranda em Contabilidade pelo Programa de Pós-Graduação em Contabilidade da (UFSC). Contato: Universidade Federal de Santa Catarina, Campus Reitor João David Ferreira Lima, Centro Socioeconômico, Trindade, Florianópolis/SC, CEP.: 88040-970. E-mail: dcbernd@hotmail.com}

\section{Marcielle Anzilago}

Doutoranda em Contabilidade pelo Programa de Pós-Graduação em Contabilidade da (UFSC). Contato: Universidade Federal de Santa Catarina, Campus Reitor João David Ferreira Lima, Centro Socioeconômico, Trindade, Florianópolis/SC, CEP.: 88040-970. E-mail: marcianzilago@gmail.com

\section{Ilse Maria Beuren}

Doutora em Controladoria e Contabilidade pela FEA/USP e Professora na Universidade Federal de Santa Catarina (UFSC). Contato: Universidade Federal de Santa Catarina, Campus Reitor João David Ferreira Lima, Centro Socioeconômico, Trindade, Florianópolis/SC, CEP.: 88040-970.

E-mail: ilse.beuren@gmail.com 


\section{Introdução}

O discurso promovido pela mídia e pela sociedade é de que as mulheres conquistam cada vez mais colocações nas organizações, na política, na economia e em outros lugares de destaque, na tentativa de reforçar a busca pela igualdade entre homens e mulheres (Andrade, Macedo \& Oliveira, 2014). Porém, esse discurso naturalizado encontra-se em dissonância com a realidade quando se analisa a divisão equânime por gêneros nos diversos ambientes de trabalho (Araújo, 2005).

Apesar da trajetória de inserção profissional das mulheres no mercado de trabalho ao longo da história, elas ainda enfrentam um mercado predominantemente masculino (Rothwell, 1985). Avanços ocorreram nas últimas décadas em relação às discussões e estudos sobre diferenças de gênero, mas ainda há discrepância nos cargos ocupados por homens e mulheres. Principalmente no que se refere ao processo de gestão, pois o preconceito e a discriminação ainda são visíveis e dificultam a presença feminina na gestão dos negócios (Gomes, 2005). Segundo Jurkus, Park e Woodard (2011), as mulheres estão sub-representadas em diversas profissões, mantendo relativamente poucas posições de tomada de decisão. Madalozzo (2011), reforça a baixa representatividade das mulheres em cargos de alto escalão. Isso também é observado na política, na administração pública e no meio acadêmico (Unmüßig, 2007).

As mulheres ainda enfrentam preconceitos e barreiras em diversas áreas do conhecimento. Decorre que as universidades se caracterizam comumente por uma cultura masculinizada (Bagilhole \& White, 2011), pois as estruturas e valores do local de trabalho são, tendenciosamente, patriarcais, masculinas e elitistas (Caplan \& Caplan, 1994). Embora se aponte para a redução de diferenças entre os gêneros em todos os campos do conhecimento, ainda se observa a sub-representação das mulheres na docência do ensino superior, como um fenômeno persistente (Husu, 2001), principalmente em oportunidades de promoção, acesso a funções de liderança e responsabilidades administrativas. Para Husu (2001), desde os momentos iniciais da carreira acadêmica, as mulheres enfrentam experiências de sexismo e discriminação de gênero, perdurando até o doutorado e se estabelecendo após o seu término.

Múltiplos fatores podem contribuir para a opção de mulheres não ingressarem no meio científico e carreiras acadêmicas, especialmente no baixo interesse pela pós-graduação stricto sensu. Backlund (2017), destaca que a jornada em direção a um doutorado pode ser considerada como problemática e pesada para os estudantes. Muitas são as expectativas por eles nutridas, mas também muitos são os desafios, conforme expõem Franke e Arvidsson (2011), tais como: alta eficiência em termos de metas, pressões de tempo e resultados relevantes, exigência de um nível de maturidade pessoal, independência e autonomia. $\mathrm{O}$ estudo de Flynn, Feild e Bedeian (2011), mostra que as mulheres tendem a avaliar alguns fatores de forma distinta dos homens em relação as seleções acadêmicas, o que pode decorrer, conforme Durso, Cunha, Neves e Teixeira (2016), de fatores motivacionais divergentes.

Esses fatores, isolados ou em conjunto com outros elementos, representam barreiras às suas carreias. Nessa perspectiva, Tabak (2002), apontam os seguintes: preconceitos, família, baixos salários, falta de oportunidades para atingir altos postos e pressões sociais. Outros ainda impedem a conciliação com programas de formação, conforme aponta Casa Nova (2014), já que dificuldades existirão, mesmo em programas que prometam a possibilidade de conciliar vida, família e trabalho. Segundo a autora, alguns problemas são conhecidos e esperados, no entanto, outros serão implícitos, decorrentes da inserção no ambiente que não foi pensado para elas e por liderança delas. 
Apesar dos desafios de frequentar um curso de pós-graduação, somados aos desafios relativos as diferenças de gênero, vem crescendo a opção pela pós-graduação e pela carreira docente entre as mulheres. Isso pode estar associado à busca por melhores condições de vida ou, ainda, devido às alterações ocorridas nos últimos anos na educação. Tal também é observado em cursos de pós-graduação de Contabilidade, que no passado eram frequentados quase que exclusivamente pelo gênero masculino. Esse movimento também é observado na profissão contábil, com uma inserção crescente de mulheres. No entanto, conforme aponta Haynes (2017), mesmo que as mulheres já tenham conseguido alcançar avanços no desenvolvimento de sua presença na profissão contábil, desigualdades ainda permanecem. Segundo a autora, a admissão de mulheres nesta profissão é o resultado de décadas de luta, pois sempre foi considerada como uma prática masculina.

Até a década passada observava-se maior predomínio do gênero masculino na área contábil, mas isso já vem diminuindo substancialmente nos cursos de graduação. Segundo Fogarty e Goldwater (2010), o desempenho acadêmico das mulheres no ensino superior e pós-graduação tem sido igualmente bom, se, não, superior ao masculino. Mota e Souza (2013), advertem que deve ocorrer um crescimento ainda maior da participação feminina na área contábil, nos próximos anos, devido às condições intelectuais e à dedicação à profissão, além de mudanças sociais da visão sobre a mulher, no âmbito profissional. Enquanto isso não ocorre, elas ainda representam cerca de apenas um terço daqueles que obtêm um doutorado (Fogarty \& Goldwater, 2010). Esse fator pode se refletir em uma falta generalizada de mulheres na docência contábil e contínua falta de diversidade de gênero na academia.

Com base no que até aqui exposto, este estudo tem como foco norteador a seguinte questão de pesquisa: a presença do gênero feminino entre os discentes dos programas de pós-graduação stricto sensu, em específico de cursos de mestrado acadêmico, mestrado profissional e doutorado em Contabilidade do Brasil, apresenta-se proporcional ao gênero masculino, no período de 2010 a 2016 ? Objetiva-se, dessa forma, verificar a presença do gênero feminino entre os discentes dos programas de pós-graduação em Ciências Contábeis do Brasil, no período de 2010 a 2016. Amplia-se assim o debate, além de favorecer a busca de ações que visem à redução da desigualdade, não somente em termos de acesso à pós-graduação, mas também de continuidade na carreira docente.

Backlund (2017), aduz que a cada dia crescem as inscrições em programas de pós-graduação, por conseguinte, há necessidade de os coordenadores supervisionarem mais os estudantes do que no passado. Um dos fatores a serem observados é a igualdade distributiva de oportunidades a um maior espectro de pessoas, seja em diversidade de gênero, racial ou condição sexual. Com oportunidades igualitárias, consoante o estudo de Haynes (2008), mulheres são mais suscetíveis do que os homens de serem excluídas ou oprimidas. Dessa forma, torna-se necessário abordar as desigualdades de gênero, em todas as partes do mundo e em diversos contextos, já que a perpetuação das desigualdades em linhas de gênero permanece contínua (Haynes 2017).

Estudos nacionais, como os de Velloso e Velho (2001), Tabak (2002), Brandão e Teixeira (2003), Melo, Lastres e Marques (2004), Godinho, Ristoff, Fontes, Xavier e Sampaio (2005), Pinto (2007), Cunha, Cornachione Jr. e Martins (2008), Nascimento e Beuren (2011), Reina, Reina, Silva e Ensslin (2012), Silva, Anzilago e Lucas (2015) e Durso et al. (2016), que exploraram a inserção da mulher na pós-graduação em outras áreas, representam contribuições à temática e indicam a necessidade de estudos também voltados à área contábil. Instiga-se verificar como ocorre a inserção das mulheres na Contabilidade, inicialmente pelo seu ingresso na pós-graduação. Portanto, essa pesquisa mostra-se relevante por investigar tanto a desigualdade quanto a presença de discentes do gênero feminino nos programas de Pós-graduação de Contabilidade, com possíveis reflexos posteriores no mercado de trabalho. 


\section{Referencial Teórico}

\subsection{Igualdade de gênero}

O termo "gênero", segundo Scott (1995), é utilizado para indicar as relações sociais entre os sexos, representando, assim, uma maneira de indicar construções sociais, a criação inteiramente social de ideias sobre os papéis adequados aos homens e às mulheres. De acordo com a autora, é uma maneira de se referir às origens exclusivamente sociais das identidades subjetivas dos homens e das mulheres. Além disso, "gênero" pode ser compreendido como uma categoria empírica ou analítica e histórica (Tilly, 1994; Scott, 1995; Saffiotti, 1997; Araújo, 2005; Tedeschi, 2007). Quando abrangido pela realidade empírica, propaga as relações históricas e as formas de existência da realidade social (Araújo, 2005), servindo de meio para produzir consequências na sociedade (Tedeschi, 2007).

O uso do termo "gênero" apareceu como contrapartida cultural do sexo biológico a partir da segunda metade da década de 1970, com mudanças substanciais nos julgamentos dos estudos das relações entre homens e mulheres na sociedade (Tedeschi, 2007). No começo do movimento feminista, a luta pela igualdade sobrepôs-se à questão da diferença, mas só na segunda metade da década de 1970 e no transcorrer dos anos 1980 que o debate sobre a igualdade versus diferença tornou-se o meio das discussões (Araújo, 2005). Considerando a diferença uma legitimidade positiva, o movimento direcionou sua luta em prol da igualdade na diferença; a partir disso, passou-se a articular diferença cultural, cultura feminina, experiência feminina e reconhecimento da diversidade cultural de gênero (Araújo, 2005).

O sentido gramatical de gênero, conforme Araújo (2005), indica seres de distintos sexos (masculino/feminino), porém, nas últimas décadas vem sendo utilizado com outros intuitos, destacando elementos culturais e domínio social, diferenciando-se do conceito de sexo com enfoque biológico. Além da visão histórica, o termo "gênero" pode ser empregado como uma categoria política para analisar a questão da igualdade e da diferença, portanto, uma nova perspectiva de interpretação e transformação da realidade social (Rothwell, 1985; Araújo, 2005). A diferença entre os seres humanos é parte da história da humanidade, presente nos mais diversos discursos (filosófico, religioso, biológico/científico, psicológico, antropológico e social), ganhando-se maior relevância, atualmente, como objeto de análise (Araújo, 2005).

Louro (1996), aduz que "gênero" se caracteriza como uma construção social feita sobre as diferenças sociais. Trata-se, portanto, do modo como essas diferenças sexuais são compreendidas em uma dada sociedade, em um grupo, em um contexto determinado por um processo histórico. Para Alvez e Pitanguy (1985), o gênero pode ser tratado como uma construção sociocultural, levando em consideração a experiência cotidiana das pessoas, suas organizações familiares e políticas, e a atribuição de diferentes papéis dentro da sociedade para homens e mulheres de acordo com os costumes de cada lugar.

Denota-se que a temática gênero pode ser percebida dentro da ótica relacional (diferença homem versus mulher), contextual/situacional (os sexos e suas construções socioculturais) e histórica (o gênero como resultado de sua contextualização histórico-social) (Scott, 1995). Segundo Meyers-Levy e Loken (2014), "uma abordagem teórica às diferenças de gênero propõe que as diferenças de gênero surgem de forças ambientais sociais, culturais, psicológicos, entre outras". Entre as outras teorias de gênero, os autores destacam as socioculturais, de reconhecer os papéis biológicos e aprender suas influências.

Diversas teorias também estão sendo incorporadas às pesquisas relacionadas à mulher, como a Critical Mass, Role Model e Glass Ceiling. A teoria Critical Mass, segundo Granovetter (1978), indica que a natureza das interações do grupo depende de seu tamanho e do tamanho de seus subgrupos, quando um subgrupo atinge um limite. A teoria Role Model, conforme Buck, Clark, Leslie-Pelecky, Lu e Cerda-Lizarraga (2008), propõe que as pessoas são mais propensas a escolher carreiras em que podem identificar um modelo no plano de carreira (carreiras femininas e masculinas). A teoria Glass Ceiling enfatiza a dificuldade de progressão de carreira das mulheres, resultando em uma sub-representação nos cargos estratégicos e, consequentemente, nas decisões (Weyer, 2007; Nascimento \& Alves, 2014). 
As problemáticas relacionadas ao fenômeno "teto de vidro" (glass ceiling) atingem as mulheres que atuam no mercado de trabalho, e são explorados, principalmente, por questões relacionadas à presença de mulheres nos mais altos escalões da hierarquia organizacional, já sendo passiveis de observação na academia (Silva, 2016). Segundo Ott (1989), ambientes dominados pelos homens podem gerar estresse e fazer com que as mulheres exibam menor desempenho. Desse modo, as mulheres estudantes de pós-graduação podem buscar programas considerados mais femininos, que possuam um quadro docente composto de mulheres. A quantidade de docentes do gênero feminino pode influenciar nas escolhas de instituições, tanto na pós-graduação como no prosseguimento de carreira docente, tendo em vista que a percepção de diversidade pelas mulheres pode indicar uma instituição mais equilibrada e uma maior oportunidade para o desenvolvimento da carreira (Flynn, Feild \& Bedeian, 2011).

Muitas podem, inclusive, sentirem-se mais confortáveis em trabalhar com professores do mesmo gênero. O estudo de Durso et al. (2016), a partir de um Índice de Autodeterminação da Motivação (IAM) dos discentes de Ciências Contábeis e Ciências Econômicas com relação à busca por uma pós-graduação stricto sensu, identificou, entre outros fatores, que as mulheres tendem a apresentar motivação mais autodeterminada em relação à pós-graduação do que os homens. Já no estudo de Flynn, Feild e Bedeian (2011), realizado com estudantes de doutorado em Administração dos EUA, explorando a associação de gênero e raça/etnia, foi constatado que as mulheres tendem a avaliar na seleção acadêmica alguns fatores como mais importantes do que os homens, no que se refere à diversidade de uma universidade e sua comunidade circundante, à simpatia familiar de um departamento/instituição, ao apoio à pesquisa e à clareza dos critérios de desempenho. Além disso, elas buscam estudar em universidades mais próximas do que homens, por tentar conciliar as atividades acadêmicas, familiares e pessoais.

Casa Nova (2012), relata em seu estudo que a presença feminina na Contabilidade, no Brasil, tem sido pouco explorada e os fenômenos como critical mass, role model, glass ceiling ou pipeline podem estar presentes. Destaca ainda que uma possibilidade de modificar o quadro da desigualdade de gêneros na área contábil é a conscientização e a instituição de políticas de apoio à classe menos favorecida. O estudo de Gomes, Corrêa e Domingos (2010), revela que a participação feminina na produção científica da área contábil, no Brasil, é significativamente menor em relação a masculina. As publicações exclusivamente femininas são reduzidas e, em grande parte, ocorrem com a participação de autores do gênero masculino.

Nesse sentido, a investigação da presença do gênero feminino entre discentes de programas de pós-graduação de Contabilidade, além de, em sua participação no âmbito da produção científica, pode ser um sinalizador da tendência destes fenômenos, que podem inclusive repercutir posteriormente na carreira acadêmica.

\subsection{Pós-graduação stricto sensu em Contabilidade no Brasil}

A necessidade de avanços do conhecimento, sob a ótica do atendimento às exigências do mercado, foi estudada por Drucker (1999). Em âmbito específico, o Ministério da Educação publicou o Plano Nacional de Pós-Graduação (PNPG), que "cabe à pós-graduação a tarefa de produzir os profissionais aptos a atuarem nos diferentes setores da sociedade e capazes de contribuir, a partir da formação recebida, para o processo de modernização do País" (CAPES, 2004, p. 8). Em comum, ambos destacam a necessidade da produção do conhecimento frente às necessidades do mercado.

Nesse sentido, insere-se a relevância das atividades da academia. Segundo a CAPES (2004, p. 8), "os dados disponíveis demonstram, sobremaneira, que é no interior do Sistema Nacional de Pós-Graduação que, basicamente, ocorre a atividade científica e tecnológica brasileira”. As incumbências e relevâncias da atuação, de acordo com a CAPES (2004), têm contado, em particular, com a evolução dos Programas de Pós-Graduação (PPGs). 
A discussão, análise e avaliação das atividades acadêmicas em nível de pós-graduação têm sido objeto de discussões e análises ao longo do tempo. Tavares (2000), ao tratar da reforma universitária realizada na década de 1970, enfatiza que esta teve como pilares a organização em departamentos, a derrubada das cátedras, a adoção do regime de dedicação exclusiva e a implantação da pós-graduação (Souza, Machado \& Bianchi, 2011).

Para Tavares (2000), a criação da pós-graduação com papel integrado à pesquisa científica pode ter sido o fato mais relevante da evolução da universidade brasileira desde a sua criação. Ainda no âmbito geral da pós-graduação, Borges (2008), destaca que a formação quantitativa e qualitativa de recursos humanos especializados é uma das etapas mais importantes para o amadurecimento de determinada área do conhecimento, pois desempenha um papel estratégico.

A pós-graduação em nível de stricto sensu, no Brasil, apresentou um crescimento evidente nos últimos anos. De 1976, ano em que teve início o processo de avaliação dos Programas de Pós-Graduação pela CAPES (2004), os cursos recomendados passaram de um total de 673 (183 doutorados), para 2.993 (1.034 doutorados), (Cunha, Cornachione Jr \& Martins, 2008).

De acordo com a CAPES (2013), o Sistema Nacional de Pós-Graduação teve um crescimento de, aproximadamente, $23 \%$ na avaliação trienal de 2013. O desenvolvimento do sistema aconteceu em todas as regiões do Brasil, sendo que a região Norte teve $40 \%$ de crescimento, seguida pelo Centro-Oeste, com $37 \%$, e Nordeste, com 33\%. O Sul e o Sudeste, regiões com maior número de programas de pós-graduação, tiveram crescimento de $25 \%$ e $14 \%$, respectivamente.

$\mathrm{Na}$ área de Ciências Contábeis, segundo dados da Sucupira (2016), atualmente, há 26 cursos de mestrado acadêmico, 5 cursos de mestrado profissional e 16 cursos de doutorado reconhecidos e em atividade. Os programas de pós-graduação em Contabilidade estão distribuídos em diversas regiões do País, mas com maior concentração nas regiões Sudeste e Sul. Inclusive, o primeiro doutorado em contabilidade no Brasil surgiu em 1978, na Faculdade de Economia, Administração e Contabilidade (FEA) da Universidade de São Paulo (USP), em São Paulo, e foi o único da área contábil no Brasil por 30 anos. Portanto, os demais cursos de doutorado em Contabilidade são mais recentes.

No estudo de Casa Nova (2014), foi observado que os 21 programas de pós-graduação em Contabilidade no Brasil, existentes na época da pesquisa, com base nas informações disponibilizadas pela CAPES, relativas ao período de 2010 a 2012, haviam formado cerca de 68 doutores e 925 mestres. Em 2012, dos 244 docentes, apenas 61 eram mulheres (25\%).

\section{Procedimentos Metodológicos}

Um estudo de natureza descritiva foi realizado a partir de dados dos programas de pós-graduação em Ciências Contábeis, relativos ao período de 2010 a 2016, extraídos da Plataforma Sucupira, da CAPES, os quais foram categorizados e arranjados quantitativamente para fins de análise.

\subsection{População e amostra}

Esse estudo tem como amostra os discentes ingressantes dos programas de pós-graduação em Ciências Contábeis, com cursos de mestrado acadêmico, mestrado profissional e de doutorado, no período de 2010 a 2016. Optou-se pelo recorte temporal de seis anos para acompanhar a evolução da presença do gênero feminino entre os discentes nos programas no período de expansão dos cursos de pós-graduação em Contabilidade no Brasil, aliados à viabilidade informacional divulgada. 
Os dados foram extraídos da Plataforma Sucupira (2016), que, de acordo com a CAPES (2014), "é uma nova e importante ferramenta para coletar informações, realizar análises e avaliações e ser a base de referência do Sistema Nacional de Pós-Graduação (SNPG)". Foram listadas 33 instituições, estabelecidas em diversas regiões do País, com diferentes designações de seus programas. No entanto, foram considerados isoladamente os mestrados profissionais, por apresentarem perfil diferenciado dos alunos matriculados em comparação aos mestrados acadêmicos. No total, foram investigados 26 cursos de mestrado acadêmico, 5 de mestrado profissional e 13 cursos de doutorado. No Quadro 1, apresenta-se a relação dos programas de pós-graduação em Ciências Contábeis do Brasil, até o ano de 2016.

Quadro 1

\section{Relação dos Programas com curso de Mestrado e/ou Doutorado em Contabilidade}

\begin{tabular}{|c|c|c|c|}
\hline Instituição & Programa & $\begin{array}{c}\text { Mestrado } \\
\text { Ano de } \\
\text { implementação }\end{array}$ & $\begin{array}{c}\text { Doutorado } \\
\text { Ano de } \\
\text { implementação }\end{array}$ \\
\hline Universidade de São Paulo (USP) & $\begin{array}{l}\text { Controladoria e } \\
\text { Contabilidade }\end{array}$ & 1970 & 1978 \\
\hline $\begin{array}{l}\text { Pontifícia Universidade Católica de São Paulo } \\
\text { (PUCSP) }\end{array}$ & $\begin{array}{l}\text { Ciências Contábeis e } \\
\text { Atuariais }\end{array}$ & 1978 & - \\
\hline Universidade Estadual do Rio de Janeiro (UERJ) & Ciências Contábeis & 1984 & - \\
\hline Universidade Federal do Rio de Janeiro (UFRJ) & Ciências Contábeis & 1998 & 2014 \\
\hline Universidade do Vale do Rio dos Sinos (UNISINOS) & Ciências Contábeis & 2000 & 2013 \\
\hline Fucape Business School (FUCAPE - ES) & Ciências Contábeis* & 2001 & - \\
\hline $\begin{array}{l}\text { Universidade da Fundação Escola de Comércio } \\
\text { Álvares Penteado (UNIFECAP) }\end{array}$ & Ciências Contábeis & 2002 & - \\
\hline Universidade Federal de Santa Catarina (UFSC) & Contabilidade & 2004 & 2013 \\
\hline Universidade Federal do Paraná (UFPR) & Contabilidade & 2005 & 2014 \\
\hline Universidade Regional de Blumenau (FURB) & Ciências Contábeis & 2005 & 2008 \\
\hline Universidade de São Paulo/Ribeirão Preto (USP/RP) & $\begin{array}{l}\text { Controladoria e } \\
\text { contabilidade }\end{array}$ & 2005 & 2013 \\
\hline Universidade Federal de Minas Gerais (UFMG) & Ciências Contábeis & 2006 & Em projeto \\
\hline Universidade Federal da Bahia (UFBA) & Contabilidade & 2007 & - \\
\hline Universidade Federal do Amazonas (UFAM) & $\begin{array}{l}\text { Contabilidade e } \\
\text { Controladoria* }\end{array}$ & $2006 * * *$ & - \\
\hline Universidade Federal de Pernambuco (UFPE) & Ciências Contábeis & 2007 & 2016 \\
\hline Universidade Presbiteriana Mackenzie (UPM) & Ciências Contábeis* & 2008 & - \\
\hline Fucape Business School (FUCAPE - ES) & Ciências Contábeis & 2009 & 2009 \\
\hline Universidade Federal do Ceará (UFC) & $\begin{array}{l}\text { Administração e } \\
\text { Controladoria * }\end{array}$ & 2009 & - \\
\hline Universidade Federal do Ceará (UFC) & $\begin{array}{l}\text { Administração e } \\
\text { Controladoria }\end{array}$ & 2009 & 2015 \\
\hline Universidade Federal do Espírito Santo (UFES) & Ciências Contábeis & 2010 & - \\
\hline Universidade de Uberlândia (UFU) & Ciências Contábeis & 2013 & 2016 \\
\hline
\end{tabular}




\begin{tabular}{|c|c|c|c|}
\hline Instituição & Programa & $\begin{array}{c}\text { Mestrado } \\
\text { Ano de } \\
\text { implementação }\end{array}$ & $\begin{array}{c}\text { Doutorado } \\
\text { Ano de } \\
\text { implementação }\end{array}$ \\
\hline Universidade de Brasília (UNB) & Ciências Contábeis & 2014 & 2014 \\
\hline Universidade Estadual de Maringá (UEM) & Ciências Contábeis & 2014 & - \\
\hline Universidade Federal do Rio Grande do Norte (UFRN) & Ciências Contábeis & 2014 & - \\
\hline Universidade Federal da Paraíba (UFPB) & Ciências Contábeis & 2014 & 2014 \\
\hline Universidade Federal Rural de Pernambuco (UFRPE) & Controladoria & 2015 & - \\
\hline $\begin{array}{l}\text { Universidade Estadual do Oeste do Paraná } \\
\text { (UNIOESTE) }\end{array}$ & Contabilidade & 2015 & - \\
\hline $\begin{array}{l}\text { Universidade Comunitária da Região de Chapecó } \\
\text { (UNOCHAPECÓ) }\end{array}$ & $\begin{array}{l}\text { Ciências Contábeis e } \\
\text { Administração }\end{array}$ & 2015 & - \\
\hline Fucape Business School (FUCAPE - RJ) & Ciências Contábeis* & 2015 & - \\
\hline $\begin{array}{l}\text { Fundação Instituto de Pesquisas Contábeis, Atuariais } \\
\text { e Financeiras (FIPECAPI) }\end{array}$ & $\begin{array}{l}\text { Controladoria e } \\
\text { Finanças* }\end{array}$ & 2016 & - \\
\hline Universidade Federal de Goiás (UFG) & Ciências Contábeis & 2016 & - \\
\hline Universidade Federal do Mato Grosso do Sul (UFMS) & Ciências Contábeis & $2016-2017 * \star$ & \\
\hline Fucape Business School (FUCAPE - MA) & $\begin{array}{l}\text { Contabilidade e } \\
\text { Administração }\end{array}$ & $2016-2017^{\star \star}$ & - \\
\hline
\end{tabular}

Legenda: *Mestrado Profissional, **Programas em acompanhamento, ***Programa descredenciado

Fonte: dados da pesquisa (2016).

Conforme exposto na Figura 1, a instituição precursora de programas de pós-graduação em Contabilidade no Brasil foi a Universidade de São Paulo (USP), criado em 1970. Os demais programas foram implementados 30 anos ou mais após a criação do primeiro, principalmente após o ano de 2000, com exceção da Pontifícia Universidade Católica de São Paulo (PUC-SP), cujo Programa foi criado em 1978, ano em que a USP implementou o curso de doutorado em Controladoria e Contabilidade.

Das 31 instituições com programa de pós-graduação em Contabilidade ativo no ano de 2016, constatou-se que 2 instituições (UFC e FUCAPE - ES), tem tanto mestrado acadêmico quanto profissional, sendo que a FUCAPE (ES), possui, além disso, doutorado. Ressalta-se que 13 programas possuem cursos de mestrado e de doutorado em Contabilidade e 13 possuem somente curso de mestrado acadêmico. Os programas da UFMS e FUCAPE (MA), constam em acompanhamento e sem dados divulgados de discentes matriculados até 2016 na base Sucupira (2016), portanto, não foram incluídos nas análises, por falta de informações. A UFAM também não foi considerada na amostra, pelo fato de o programa ter sido descredenciado na avaliação trienal 2010-2012.

No total, foram investigados 26 cursos de mestrado acadêmico, 5 de mestrado profissional e 13 de doutorado. Identificou-se um o total de 3.013 discentes ingressantes no período de 2010 a 2016, dos quais 2.058 são de mestrado acadêmico, 530 de mestrado profissional e 451 de doutorado, conforme demonstrado na Tabela 1. 
Tabela 1

Discentes ingressantes nos cursos de mestrado acadêmico e profissional e no doutorado (2010 a 2016)

\begin{tabular}{|c|c|c|c|c|c|c|}
\hline Sigla da IES & Estado & Macrorregião & $\begin{array}{l}\text { Mestrado } \\
\text { Profissional }\end{array}$ & Mestrado & Doutorado & Totais \\
\hline UFC & $\mathrm{CE}$ & \multirow{6}{*}{ Nordeste } & 170 & 128 & - & 298 \\
\hline UFBA & $\mathrm{BA}$ & & - & 76 & - & 76 \\
\hline UFPB & PB & & - & 30 & 14 & 44 \\
\hline UFRN & RN & & - & 20 & - & 20 \\
\hline UFRPE & PE & & - & 29 & - & 29 \\
\hline UFPE & $\mathrm{PE}$ & & - & 81 & 6 & 87 \\
\hline UnB* & DF & \multirow{3}{*}{ Centro-Oeste } & - & 80 & 70 & 150 \\
\hline UnB & DF & & - & 32 & 22 & 54 \\
\hline UFG & GO & & - & 18 & - & 18 \\
\hline UFMG & MG & \multirow{11}{*}{ Sudoeste } & - & 62 & - & 62 \\
\hline UFU & MG & & - & 65 & 8 & 73 \\
\hline FUCAPE & ES & & 122 & 41 & 14 & 177 \\
\hline UFES & ES & & - & 85 & - & 85 \\
\hline UERJ & RJ & & - & 113 & - & 113 \\
\hline UFRJ & $\mathrm{RJ}$ & & - & 99 & 20 & 119 \\
\hline FUCAPE & $\mathrm{RJ}$ & & 18 & - & - & 18 \\
\hline PUC/SP & SP & & - & 175 & - & 175 \\
\hline USP & SP & & - & 95 & 119 & 214 \\
\hline USP/RP & SP & & - & 82 & 30 & 112 \\
\hline UNIFECAP & SP & & - & 139 & - & 139 \\
\hline FIPECAFI & SP & \multirow{9}{*}{ Sul } & 35 & - & - & 35 \\
\hline UPM & SP & & 185 & - & - & 185 \\
\hline UEM & PR & & - & 48 & - & 48 \\
\hline UFPR & PR & & - & 118 & 18 & 136 \\
\hline UNIOESTE & PR & & - & 30 & - & 30 \\
\hline FURB & SC & & - & 83 & 52 & 135 \\
\hline UFSC & SC & & - & 117 & 24 & 141 \\
\hline UNOCHAPECÓ & SC & & - & 33 & - & 33 \\
\hline UNISINOS & RS & & - & 179 & 28 & 207 \\
\hline Totais & & & 530 & 2.058 & 451 & 3.013 \\
\hline
\end{tabular}

Legenda: *parceria da UnB com UFRN e UFPB

Fonte: dados da pesquisa (2016).

Verifica-se na Tabela 1, que as IES investigadas são oriundas de 14 estados. Os estados com maior número de programas de pós-graduação em Contabilidade são: São Paulo, 4 IES com programas (PUC/ SP, USP, USP/RP e UNIFECAP). A distribuição dos Programas por regiões é a seguinte: Sudeste (13), Sul (7), Nordeste (6) e Centro-Oeste (2). A região Norte não registrou Programa de Pós-graduação em Contabilidade em exercício em 2016. 


\subsection{Tratamento dos dados}

Inicialmente identificaram-se todos os programas de pós-graduação em Contabilidade com cursos de mestrado acadêmico, mestrado profissional e doutorado, até o ano de 2016. Na sequência, foi investigada individualmente cada IES, nos triênios de 2010-2012 e 2013-2016, a fim de averiguar a quantidade de discentes matriculados. Esses dados foram coletados na Plataforma Sucupira (2016), da CAPES.

Alguns dados foram buscados ou confirmados isoladamente, por ano, na plataforma Sucupira, ou ainda no website dos programas, principalmente no ano de 2010. Após terem sido selecionados os discentes ingressantes de cada IES, em seus respectivos anos, eles foram categorizados por gênero e quantificados por período, segundo cada modalidade de ingresso nos cursos (mestrado acadêmico, mestrado profissional e doutorado). Analisaram-se as suas evoluções em ternos de anos e suas concentrações de acordo com as macrorregiões brasileiras. Também foram realizadas análises estatísticas descritivas dos dados.

\section{Descrição e Análise dos Resultados}

\subsection{Discentes por gênero nos programas de pós-graduação em Ciências Contábeis}

Na Tabela 2, apresenta-se a quantidade de discentes ingressantes no período de 2010 a 2016, nos cursos de mestrado profissional em Contabilidade, classificados por gênero.

Tabela 2

Quantidade de discentes ingressantes no mestrado profissional segundo o gênero (2010 a 2016)

\begin{tabular}{|c|c|c|c|c|c|c|c|c|c|c|c|c|c|c|c|c|c|c|}
\hline \multirow[t]{2}{*}{ IES } & \multicolumn{2}{|c|}{2010} & \multicolumn{2}{|c|}{2011} & \multicolumn{2}{|c|}{2012} & \multicolumn{2}{|c|}{2013} & \multicolumn{2}{|c|}{2014} & \multicolumn{2}{|c|}{2015} & \multicolumn{2}{|c|}{2016} & \multicolumn{2}{|c|}{ Total Geral } & \multicolumn{2}{|c|}{ Total \% } \\
\hline & $\mathrm{F}$ & $M$ & $F$ & $M$ & $\mathrm{~F}$ & $M$ & $F$ & $M$ & $\mathrm{~F}$ & $M$ & $\mathrm{~F}$ & $M$ & $\mathrm{~F}$ & $M$ & $\mathrm{~F}$ & $M$ & $\mathrm{~F}$ & $M$ \\
\hline UFC & 1 & 0 & 12 & 16 & 25 & 30 & 22 & 16 & * & * & 10 & 12 & 14 & 12 & 84 & 86 & $49 \%$ & $51 \%$ \\
\hline UPM & & 5 & 1 & 19 & 11 & 24 & 10 & 27 & 7 & 19 & 7 & 24 & 14 & 17 & 50 & 135 & $27 \%$ & $73 \%$ \\
\hline FUCAPE/ES & & & 9 & 22 & 8 & 20 & 8 & 14 & 1 & 10 & 5 & 11 & 5 & 9 & 36 & 86 & $30 \%$ & $70 \%$ \\
\hline FUCAPE/RJ & & & & & & & & & & & 8 & 6 & 3 & 1 & 11 & 7 & $61 \%$ & $39 \%$ \\
\hline FIPECAFI & & & & & & & & & & & & & 8 & 27 & 8 & 27 & $23 \%$ & $77 \%$ \\
\hline Total Geral & 1 & 5 & 22 & 57 & 44 & 74 & 40 & 57 & 8 & 29 & 30 & 53 & 44 & 66 & 189 & 341 & $36 \%$ & $64 \%$ \\
\hline Total \% & $17 \%$ & $83 \%$ & $28 \%$ & $72 \%$ & $37 \%$ & $63 \%$ & $41 \%$ & $59 \%$ & $22 \%$ & $78 \%$ & $36 \%$ & $64 \%$ & $40 \%$ & $60 \%$ & $36 \%$ & $64 \%$ & & \\
\hline
\end{tabular}

Legenda: *não encontrado na Plataforma Sucupira

Fonte: dados da pesquisa (2016).

Observa-se na Tabela 2, a quantidade de discentes dos gêneros feminino e masculino nos cursos de mestrado profissional, os quais, em sua maioria, concentram-se na região Sudeste, com exceção da UFC, que se localiza na região Nordeste. Os dados revelam diferenças no que concerne a quantidade de mulheres matriculadas (36\%), comparativamente aos homens (64\%), com destaque particular à UPM (73\%) e à FUCAPE/ES (70\%) de supremacia masculina.

Segundo o Conselho Federal de Contabilidade (CFC, 2016), na média nacional, 57\% dos registros ativos nos Conselhos Regionais de Contabilidade (CRCs) são do gênero masculino. Na região Nordeste, cerca de 59\% são homens; nas regiões Sul e Sudeste, 57\%; na Centro-Oeste, 58\%; e no Distrito Federal, $54 \%$. Como existem mais homens atuando na área contábil, a procura destes profissionais por cursos de pós-graduação na área também é maior. 
Na Tabela 3, apresenta-se a quantidade de ingressantes nos cursos de mestrado acadêmico, no período de 2010 a 2016.

Tabela 3

Quantidade de discentes ingressantes no mestrado acadêmico segundo o gênero (2010 a 2016)

\begin{tabular}{|c|c|c|c|c|c|c|c|c|c|c|c|c|c|c|c|c|c|c|}
\hline \multirow[t]{2}{*}{ IES } & \multicolumn{2}{|c|}{2010} & \multicolumn{2}{|c|}{2011} & \multicolumn{2}{|c|}{2012} & \multicolumn{2}{|c|}{2013} & \multicolumn{2}{|c|}{2014} & \multicolumn{2}{|c|}{2015} & \multicolumn{2}{|c|}{2016} & \multicolumn{2}{|c|}{$\begin{array}{l}\text { Total } \\
\text { Geral }\end{array}$} & \multicolumn{2}{|c|}{ Total \% } \\
\hline & $\mathrm{F}$ & M & $\mathrm{F}$ & M & $\mathrm{F}$ & M & $\mathrm{F}$ & $M$ & $\mathrm{~F}$ & M & $\mathrm{F}$ & M & $\mathrm{F}$ & M & $\mathrm{F}$ & M & $\mathrm{F}$ & M \\
\hline UFC & 8 & 6 & 9 & 5 & 12 & 6 & 7 & 9 & 5 & 6 & 10 & 16 & 16 & 13 & 67 & 61 & $52 \%$ & $48 \%$ \\
\hline UFBA & 1 & 2 & 3 & 4 & 5 & 6 & 7 & 7 & 4 & 10 & 3 & 9 & 6 & 9 & 29 & 47 & $38 \%$ & $62 \%$ \\
\hline UFPB & & & & & & & & & & & 7 & 8 & 9 & 6 & 16 & 14 & $53 \%$ & $47 \%$ \\
\hline UFRN & & & & & & & & & & & 6 & 4 & 5 & 5 & 11 & 9 & $55 \%$ & $45 \%$ \\
\hline UFRPE & & & & & & & & & & & 5 & 8 & 7 & 9 & 12 & 17 & $41 \%$ & $59 \%$ \\
\hline UFPE & 0 & 1 & 5 & 3 & 5 & 9 & 5 & 11 & 6 & 6 & 6 & 7 & 7 & 10 & 34 & 47 & $42 \%$ & $58 \%$ \\
\hline UnB* & 1 & 1 & 1 & 4 & 16 & 19 & 8 & 9 & 10 & 11 & & & & & 36 & 44 & $45 \%$ & $55 \%$ \\
\hline UnB & & & & & & & & & & & 7 & 8 & 9 & 8 & 16 & 16 & $50 \%$ & $50 \%$ \\
\hline UFG & & & & & & & & & & & & & 8 & 10 & 8 & 10 & $44 \%$ & $56 \%$ \\
\hline UFMG & 1 & 4 & 2 & 2 & 2 & 9 & 3 & 6 & 6 & 2 & 6 & 6 & 6 & 7 & 26 & 36 & $42 \%$ & $58 \%$ \\
\hline UFU & & & & & & & 8 & 8 & 5 & 3 & 12 & 8 & 10 & 11 & 35 & 30 & $54 \%$ & $46 \%$ \\
\hline FUCAPE & & & 2 & 1 & 1 & & 2 & 1 & 3 & 6 & 8 & 14 & & 3 & 16 & 25 & $39 \%$ & $61 \%$ \\
\hline UFES & 2 & 2 & 2 & 5 & 4 & 10 & 2 & 10 & 6 & 4 & 5 & 10 & 11 & 12 & 32 & 53 & $38 \%$ & $62 \%$ \\
\hline UERJ & & & 4 & 11 & 7 & 11 & 9 & 11 & 11 & 9 & 13 & 7 & 5 & 15 & 49 & 64 & $43 \%$ & $57 \%$ \\
\hline UFRJ & 6 & 2 & 2 & 5 & 5 & 7 & 8 & 10 & 7 & 16 & 4 & 7 & 4 & 16 & 36 & 63 & $36 \%$ & $64 \%$ \\
\hline PUC/SP & 0 & 2 & 3 & 21 & 15 & 21 & 7 & 20 & 7 & 14 & 14 & 28 & 6 & 17 & 52 & 123 & $30 \%$ & $70 \%$ \\
\hline USP & 4 & 11 & 4 & 13 & 10 & 8 & 9 & 9 & 2 & 3 & 3 & 5 & 6 & 8 & 38 & 57 & $40 \%$ & $60 \%$ \\
\hline USP/RP & 2 & 2 & 3 & 7 & 5 & 13 & 6 & 9 & 11 & 1 & 4 & 5 & 5 & 9 & 36 & 46 & $44 \%$ & $56 \%$ \\
\hline UNIFACAP & 1 & 1 & 3 & 6 & 20 & 23 & 6 & 19 & 5 & 15 & 8 & 14 & 6 & 12 & 49 & 90 & $35 \%$ & $65 \%$ \\
\hline UEM & & & & & & & & & 13 & 1 & 6 & 11 & 11 & 6 & 30 & 18 & $63 \%$ & $38 \%$ \\
\hline UFPR & 5 & 5 & 6 & 9 & 7 & 9 & 10 & 8 & 11 & 9 & 5 & 9 & 11 & 14 & 55 & 63 & $47 \%$ & $53 \%$ \\
\hline UNIOESTE & & & & & & & & & & & 6 & 9 & 9 & 6 & 15 & 15 & $50 \%$ & $50 \%$ \\
\hline FURB & 2 & 5 & 8 & 3 & 3 & 9 & 11 & 4 & 4 & 5 & 7 & 7 & 13 & 2 & 48 & 35 & $58 \%$ & $42 \%$ \\
\hline UFSC & 8 & 5 & 13 & 5 & 6 & 9 & 13 & 8 & 8 & 6 & 12 & 8 & 8 & 8 & 68 & 49 & $58 \%$ & $42 \%$ \\
\hline UNOCHAPECÓ & & & & & & & & & & & 6 & 9 & 12 & 6 & 18 & 15 & $55 \%$ & $45 \%$ \\
\hline UNISINOS & 9 & 4 & 17 & 24 & 10 & 10 & 8 & 23 & 5 & 8 & 20 & 21 & 7 & 13 & 76 & 103 & $42 \%$ & $58 \%$ \\
\hline Total Geral & 50 & 53 & 87 & 128 & 133 & 179 & 129 & 182 & 129 & 135 & 183 & 238 & 197 & 235 & 908 & 1150 & $44 \%$ & $56 \%$ \\
\hline Total \% & $49 \%$ & $51 \%$ & $40 \%$ & $60 \%$ & $43 \%$ & $57 \%$ & $41 \%$ & $59 \%$ & $49 \%$ & $51 \%$ & $43 \%$ & $57 \%$ & $46 \%$ & $54 \%$ & $44 \%$ & $56 \%$ & & \\
\hline
\end{tabular}

Nota: Instituições agrupadas em tons cinza por macrorregiões brasileiras: Nordeste, Centro-Oeste, Sudeste e Sul.

Legenda: * parceria UnB com UFRN e UFPB

Fonte: dados da pesquisa (2016).

Observa-se na Tabela 3, que o número total de ingressantes do gênero feminino (44\%) foi menor do que o masculino (56\%), com uma diferença percentual de $12 \%$. Os cursos de mestrado acadêmico que apresentaram número superior de mulheres ingressantes em comparação com homens, no período de 2010 a 2016, foram: UEM (63\%), FURB e UFSC (58\%), UNOCHAPECÓ (55\%), UFRN (55\%), UFU (54\%), UFPB (53\%) e UFC (52\%). Os demais apresentaram maior número de discentes ingressantes do gênero masculino, com destaque à PUC/SP (70\%), UNIPECAP (65\%), UFRJ (64\%) e FUCAPE (61\%).

Se observadas as diferenças anuais de ingressantes do gênero feminino, notam-se mudanças ao longo do período. Na Figura 2, apresenta-se a evolução, ao longo dos anos (2010-2016), das matrículas de discentes nos cursos de mestrado acadêmico dos programas relacionados na Tabela 3, por gênero. 


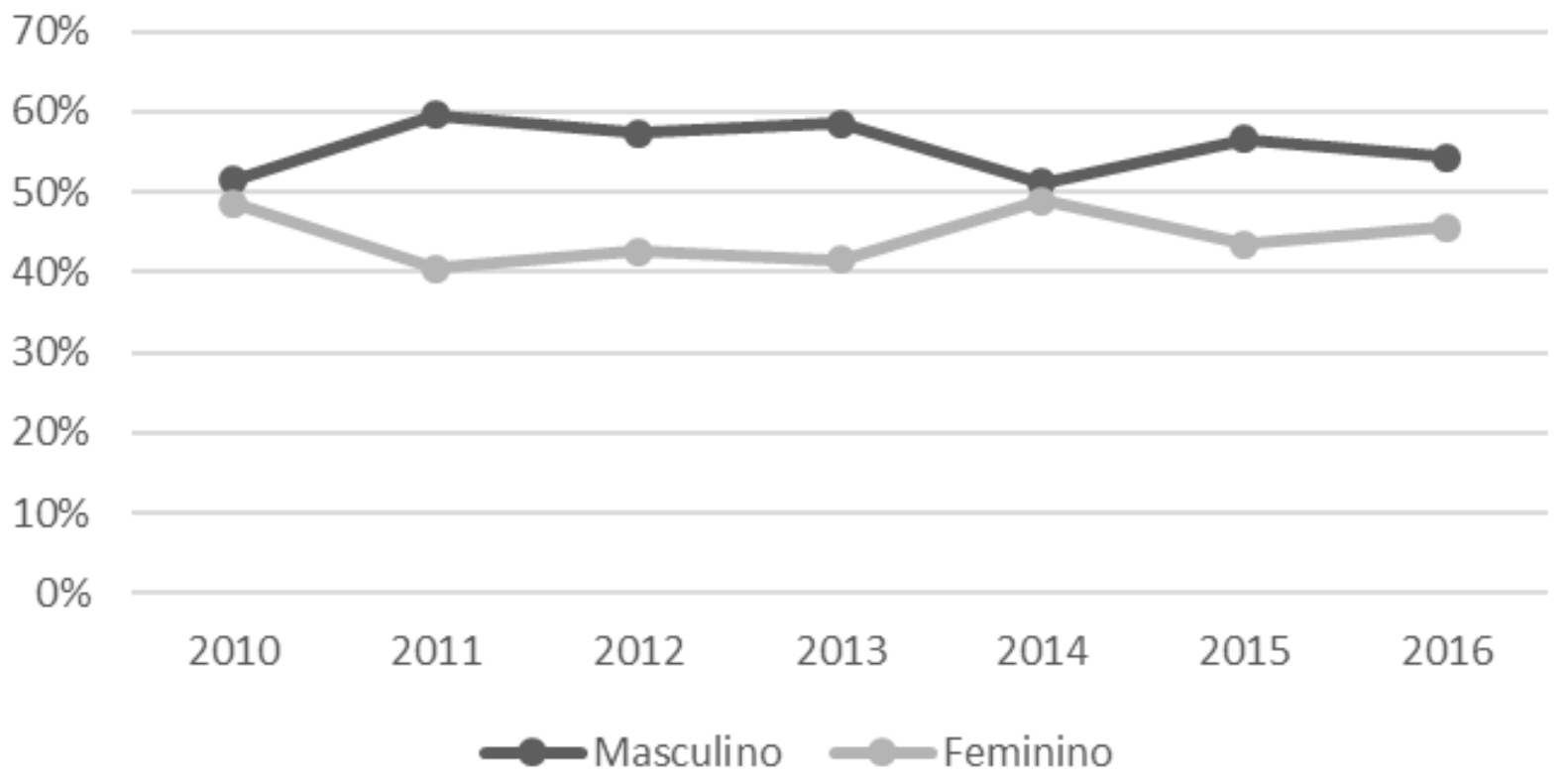

Figura 1. Evolução de qualidade percentual de matrículas de discentes no mestrado acadêmico (2010-2016) Fonte: Dados da pesquisa.

Nota-se, na Figura 1, proximidade entre o número de ingressantes do gênero feminino e masculino em 2010, e sua redução nos anos seguintes. Em 2010, 51\% das vagas foram ocupadas pelo gênero masculino e $49 \%$ pelo gênero feminino. Esse quase equilíbrio decorre principalmente de um maior número de matrículas do gênero feminino na UNISINOS, UFSC, UFRJ e UFC, conforme pode-se observar na Tabela 2. No entanto, estes percentuais não foram mantidos, pois de 2011 a 2013, em média, 58\% dos ingressantes foram do gênero masculino. Já em 2014, foi quase igualitária (49\% mulheres e 51\% homens), mas voltando para 57\% de ingressantes do gênero masculino em 2015 e 54\% em 2016. Em 2014, várias instituições tiveram ingressos superiores do gênero feminino, com destaque à USP/RP, com 100\% de mulheres. Nesse ano também a região Sul apresentou ingresso maior do gênero feminino (59\%).

A pesquisa realizada pelo AICPA (2015) revelou que, no período de 2010-2014, a distribuição por gênero de graduados como bacharel e mestre na área contábil manteve-se, em média, 52\% para o gênero masculino e $48 \%$ para o feminino nos EUA. Os dados da pesquisa ainda revelaram que a quantidade de ingressantes masculinos no mesmo período (2010-2014) foi, em média, de 56\%. No Brasil, observa-se uma diferença superior ao indicado pelo AICPA, com menor ingresso de mulheres nacionalmente do que nos EUA. Para verificar se isso ocorre de forma equivalente em todas as regiões brasileiras, apresenta-se a Figura 2. 


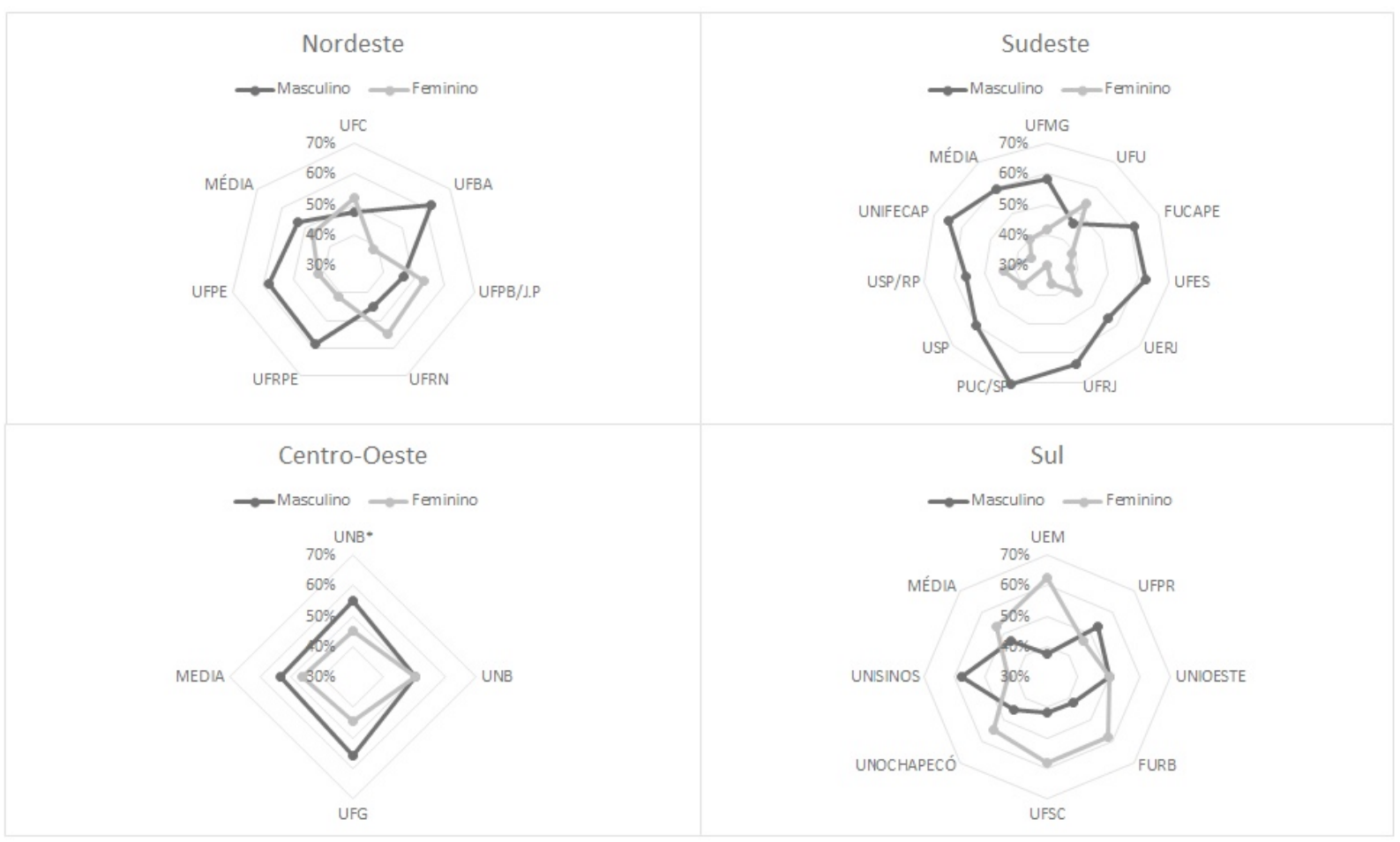

Figura 2. Percentuais de matrículas no mestrado acadêmico por macrorregiões dos Programas (2010-2016) Legenda: *parceria da UnB com UFRN e UFPB

Fonte: dados da pesquisa.

Observa-se na Figura 3, que a região Nordeste teve, em média, 53\% de ingressos do gênero masculino. Embora a UFRN (55\%), UFPB (53\%) e UFC (52\%), tenham apresentado índices superiores de ingressos de mulheres, a UFBA (62\%), UFRPE (59\%) e UFPE (58\%) apresentaram ingressos maiores de homens no período analisado.

No Centro-Oeste, mesmo com uma representação menor, observa-se que apresentou percentuais próximos ao da região Nordeste (54\% masculino), sendo que a UnB (2011-2014) apresentou índice de $55 \%$ de ingressos do gênero masculino e a UFG (56\%).

O Sudeste apresentou uma média de $60 \%$ de ingressos do gênero masculino. Os destaques são para a PUC/SP (70\%), UFRJ (64\%), UNIFECAP (63\%), UFES (62\%) e FUCAPE (61\%), que apresentaram níveis mais elevados de matriculados do gênero masculino. Apenas a UFU apresentou, em média, ingressos superiores de mulheres (54\%), sendo que as demais instituições, USP, USP/RP, UFMG e UERJ, também apresentaram maior número de ingressantes masculinos.

A região Sul é a única que apresenta ao longo do período investigado uma média de ingressantes do gênero feminino (53\%) superior ao masculino (47\%) nos cursos de mestrado acadêmico de Contabilidade. Com destaque à UEM (63\%), FURB (58\%), UFSC (58\%) e UNOCHAPECÓ (55\%), com ingresso superior de mulheres. A UNIOESTE (50\%), manteve índices iguais para ambos os gêneros. Apenas a UNISINOS (58\%) e a UFPR (53\%), apresentaram proporções maiores de ingresso masculino nos cursos de mestrado acadêmico.

De acordo com Brandão e Teixeira (2003), as mulheres já conseguiram ultrapassar questões que envolvem o gênero ou diferenças quanto aos níveis de escolaridade entre homens e mulheres em termos de graduação. No entanto, como destaca Pinto (2007), o mesmo fator ainda não acontece na pós-graduação, o que corrobora os resultados desta pesquisa em programas de pós-graduação de Contabilidade. 
$\mathrm{Na}$ Tabela 4, apresentam-se as relações do ingresso de doutorandos nos programas de pós-graduação em Contabilidade do Brasil.

Tabela 4

Quantidade de discentes ingressantes no doutorado segundo o gênero (2010 a 2016)

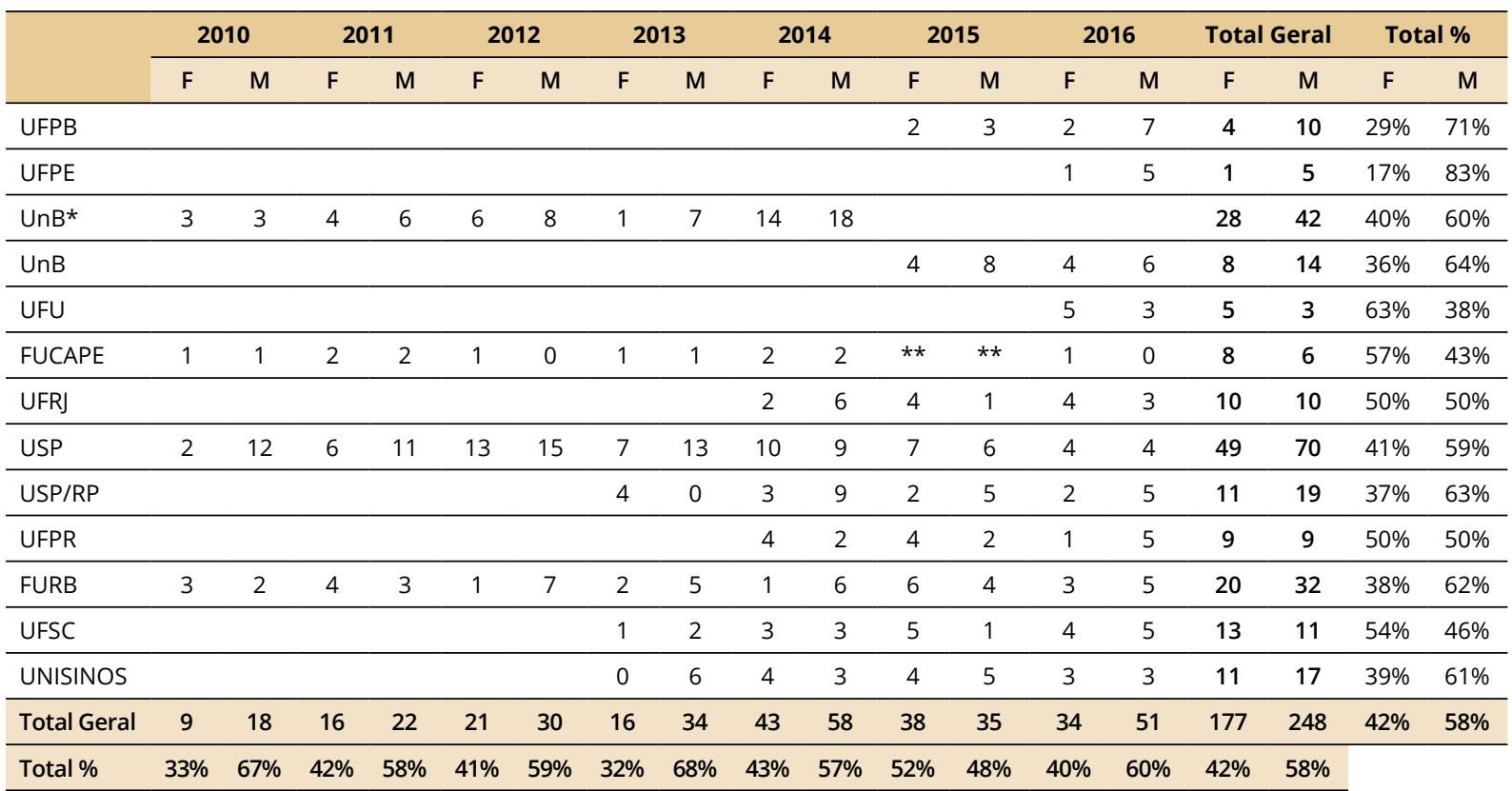

Legenda: * parceria da UnB com UFRN e UFPB; **Não identificado.

Fonte: dados da pesquisa (2016).

Observa-se na Tabela 4, que das 451 vagas preenchidas por discentes nos cursos de doutorado em Contabilidade, no período de 2010 a 2016, cerca de $42 \%$ são do gênero feminino e $58 \%$ masculino. Esses números são próximos, comparativamente, ao total de ingressos no mestrado acadêmico (Tabela 3), mas para o doutorado o ingresso foi diferente ao longo do tempo, principalmente em 2010.

Analisando-se o total de cada instituição, nota-se que a UFU (63\%), FUCAPE (57\%) e UFSC (54\%), apresentaram número de mulheres ingressantes nos cursos de doutorado superior ao de homens no período de 2010 a 2016. Em contrapartida, todas as demais instituições apresentaram números superiores de ingressantes do gênero masculino, com destaque para a UFPE (83\%), UFPB (71\%), UnB (64\%), USP/ RP e FURB (62\%).

Se analisado anualmente, observa-se que em 2015 o número de matrículas femininas chega a superar ao ingresso masculino, como pode ser observado na Figura 4. 


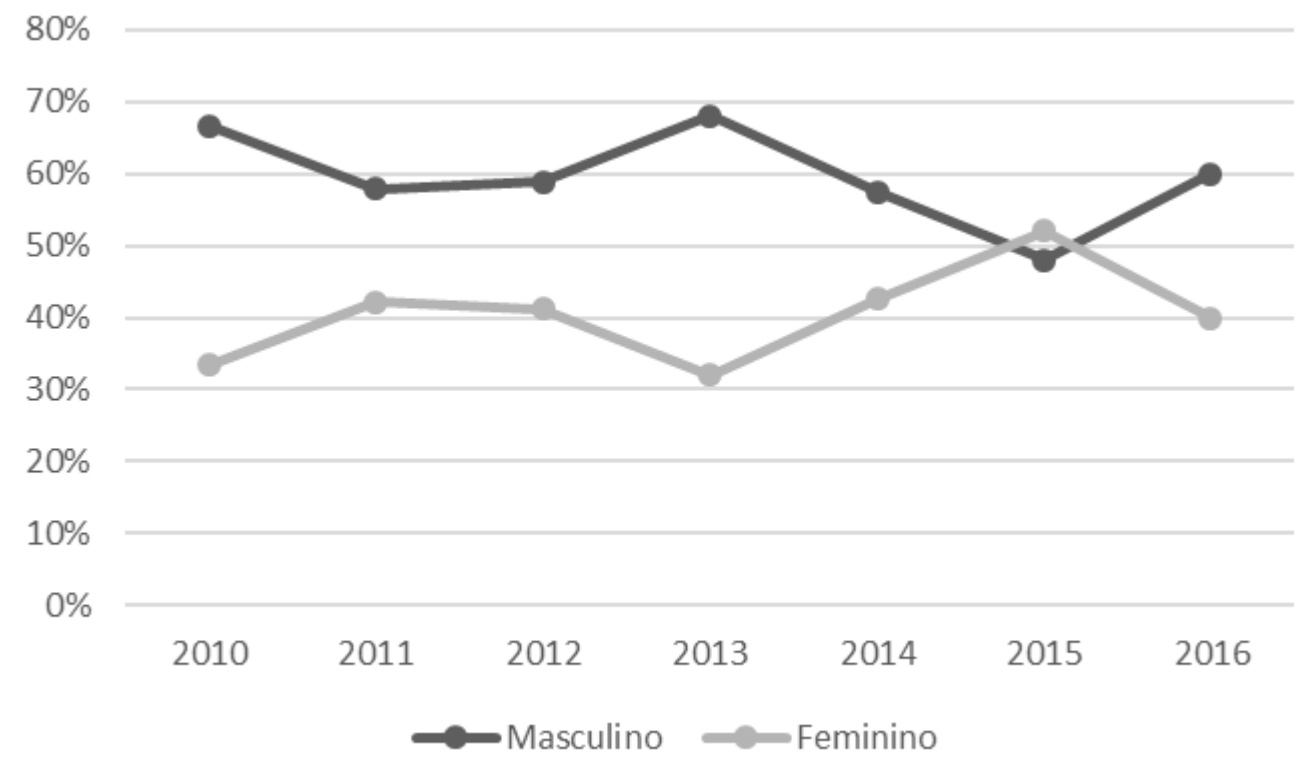

Figura 3. Evolução percentual da quantidade de matrículas de discentes no doutorado (2010-2016)

Fonte: dados da pesquisa.

De acordo com a Figura 3, ao longo dos anos, os percentuais de ingressos femininos nos cursos de doutorado apresentaram-se diferentes. Em 2010, cerca de 67\% dos ingressos era do gênero masculino, reduzindo em 2011 e 2012 para aproximadamente, 58\%. No entanto, teve um aumento de ingressantes masculinos em 2013, chegando a $68 \%$, contra 32\% do gênero feminino. A diferença pode ser decorrente do ingresso masculino superior, em cerca de $30 \%$ na USP, $75 \%$ na UnB e de $100 \%$ na UNISINOS, neste mesmo período. Em 2014, obteve-se uma proporção de 57\% masculina; já em 2015 o número de ingressos femininos foi de 52\%. O aumento de matrículas femininas em 2015 foi principalmente influenciado pelo maior ingresso na região Sul, cerca de $61 \%$, mas a região Sudeste também influenciou, com $52 \%$ de mulheres matriculadas. No entanto, em 2016 observa-se uma proporção de ingressantes masculinos de 60\%. Poucas instituições tiveram ingresso feminino superior, nesse ano, como foi o caso da UFU, FUCAPE e UFRJ, ou equilibrada como a USP.

Na Figura 4, observam-se as diferentes distribuições a partir das macrorregiões e as proporções de acordo com os cursos de doutorado em Contabilidade.

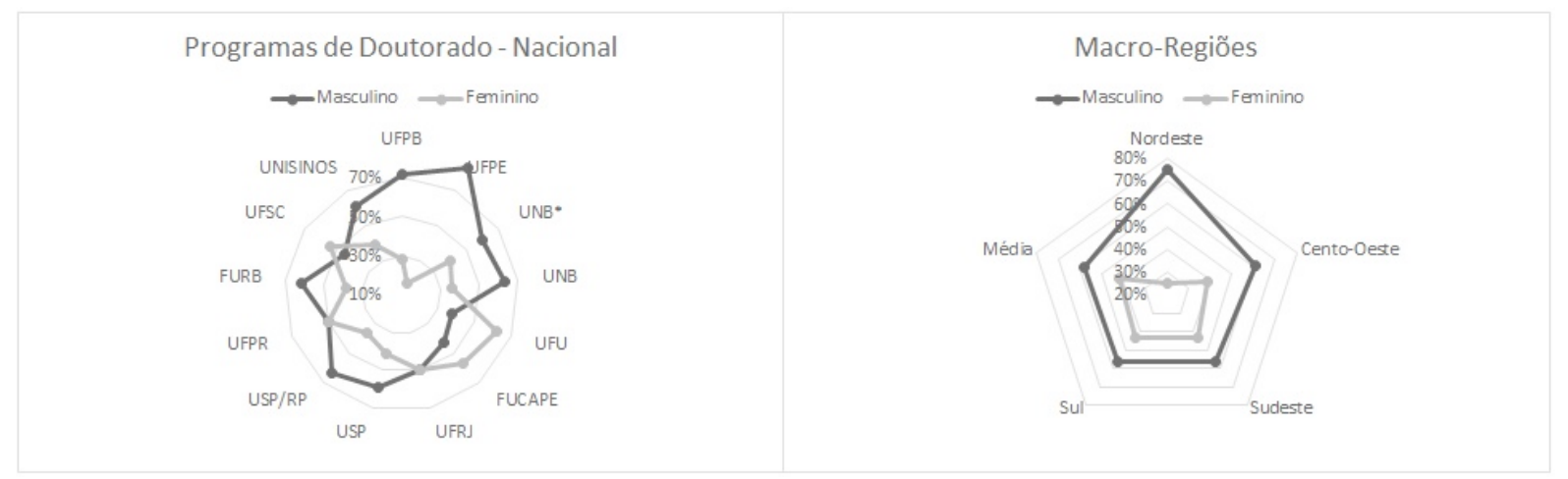

Figura 4. Percentuais de matrículas no doutorado por macrorregiões brasileiras dos Programas (2010-2016) Fonte: dados da pesquisa. 
Em geral, observa-se na Figura 5, que as regiões Sudeste e Sul apresentam igualmente os percentuais de $57 \%$ para homens e $43 \%$ para mulheres de ingresso nos cursos de doutorado no período analisado. No entanto, pelo número de programas destas regiões ser mais numeroso, os dados devem ser interpretados com cautela, quando comparados com programas mais recentes ou menos numerosos. Além disso, a UnB, na região Centro-Oeste, no período de 2010 a 2016 possui um total médio de $61 \%$ de ingressantes do gênero masculino, porém, até o ano de 2014 possuía parceria com programas do Nordeste (UFPB e UFRN). Na região Centro-Oeste, o total de matriculados do gênero feminino em âmbito do mestrado acadêmico foi de $46 \%$, e para o doutorado 39\%. Portanto, uma diferença de $7 \%$ a menos de mulheres nos cursos de doutorado.

No Nordeste, os cursos de doutorado da UFPB e UFPE, mesmo que se avaliando apenas os anos de 2015 e 2016, por serem cursos de doutorado mais recentes, apresentam um ingresso mais expressivo masculino - em média $75 \%$-, sendo que na UFPE chegou a representar mais de $83 \%$. Nesta Região, observa-se que no doutorado tem-se uma redução percentual do total de ingressantes femininos em comparação ao mestrado. A diferença chega a ser de $22 \%$, pois o ingresso feminino nos cursos de mestrado acadêmico, no período analisado, era de $47 \%$. Isso indica que o acesso de mulheres ao doutorado é mais reduzido no Nordeste comparativamente ao mestrado, tal como ocorre no Centro-Oeste.

A região Sudeste apresentou algumas instituições que tiveram ingressos do gênero feminino mais expressivos do que o masculino, como na UFU (63\%) e FUCAPE (57\%), e equilibrados, como na UFRJ (50\%). Porém, a USP/RP (63\%) e USP (59\%), não evidenciaram o mesmo padrão, com ingressos masculinos mais substanciais, sendo que a média para o Sudeste foi de $57 \%$ de homens nos cursos de doutorado em Contabilidade. Embora com percentuais distintos, a região apresentou números próximos com os ingressos dos cursos de mestrado acadêmico. No entanto, a FUCAPE (61\%), apresentou no mestrado acadêmico maior participação masculina do que no doutorado (43\%), assim como na UFRJ, que no mestrado acadêmico teve ingresso mais masculino (64\%), não se repetindo no doutorado (50\%). O mesmo fator não ocorreu na USP/RP, que teve mais ingressos masculinos no doutorado (63\%) do que no mestrado (56\%).

Na região Sul, a média também foi superior nos ingressantes do gênero masculino (57\%), comparativamente, ao feminino ( $43 \%$ ), no que se refere ao total de matrículas realizadas nos cursos de doutorado. No entanto, a UFSC apresentou ingressos mais expressivos de mulheres (54\%) e a UFPR (50\%), igualdade para ambos gêneros. Já a FURB e a UNISINOS ultrapassaram $60 \%$ de matrículas para o gênero masculino no curso de doutorado. A FURB apresentou um percentual feminino (58\%) maior no mestrado, não mantendo o mesmo padrão no curso de doutorado. Em média, nos cursos de mestrado acadêmico percebeu-se maior número de ingressantes femininos do que nos de doutorado nesta região.

De modo complementar, foi investigada, na Plataforma Sucupira (2016), a estrutura do corpo docente dos programas de pós-graduação em Contabilidade no Brasil. Nesse levantamento, observou-se que, em média, os programas possuem uma maioria masculina - cerca de $74 \%$ - contra $26 \%$ de mulheres. Em algumas intuições, a diferença chega a ser maior do que 75\%, com uma alta concentração masculina no corpo docente, tanto na região Sudeste (FUCAPE 100\%, PUC/SP 92\%, USP 88\%, USP/RP 78\%, UFES $77 \%$ ), na região Sul (UNOCHAPECÓ 100\%, UNISINOS 93\%, UFPR 85\%), como na região Nordeste (UFRN 85\%, UFPE 83\%, UFPB 79\%). Estes dados coadunam com os achados de Casa Nova (2014), que apontou em 2012 que 75\% do corpo docente dos Programas stricto sensu de Contabilidade no Brasil era composto de homens. Observa-se que esse número não se alterou nos últimos anos.

Se observado por regiões, o Sul e o Sudeste apresentaram os mesmos percentuais médios de docentes do gênero masculino nos Programas (78\%), seguidos da região Centro-Oeste (73\%) e Nordeste (66\%). Além desse aspecto, verificou-se que dos docentes que exercem outras atividades e possuem vínculo parcial com a instituição do programa ocorre um predomínio masculino, cerca de $83 \%$. Destaca-se que, mesmo que as mulheres figurem com uma sub-representação na maioria dos Programas do País, possuem predominantemente dedicação exclusiva às atividades docentes e de pesquisa. 


\subsection{Discussão dos resultados da pesquisa}

Os resultados dessa pesquisa, no geral, mostram que, tanto para os cursos de mestrado acadêmico e mestrado profissional, quanto de doutorado em Contabilidade, o número de ingressantes do gênero masculino é superior ao feminino. Em algumas regiões e instituições a diferença de ingressantes ultrapassa em $20 \%$, como no caso da região Sudeste. Com base no período amostral investigado, infere-se que o acesso de discentes do gênero masculino nos programas de pós-graduação em Ciências Contábeis do Brasil é superior ao feminino e que características regionais e institucionais podem trazer implicações às evidências.

Esses números encontram ressonância nos resultados de algumas pesquisas, embora com escopo distinto, mas com parcimônia podem revelar indícios nesta direção. Pinto (2007) averiguou o perfil racial e de gênero dos cursos de mestrado da Universidade Federal Fluminense (UFF), no período de 2004 a 2006. Os resultados revelaram desigualdades de participação entre homens e mulheres nos cursos de mestrado, além de desigualdade racial. Por exemplo, no mestrado em Economia, a participação masculina foi de 58,7\%.

Tabak (2002), aponta diversas barreiras para uma maior integração das mulheres no meio acadêmico, tais como: preconceitos, casamento, filhos, baixos salários, falta de oportunidades para atingir altos postos e pressões sociais. Esses aspectos podem contribuir para a predominância de discentes do gênero masculino nos cursos de pós-graduação. Velloso e Velho (2001), destacam que o Brasil é considerado um país central ou periférico, que tende a apresentar baixa participação feminina nos corpos docentes universitários, assim como em altos postos das hierarquias do sistema de ensino superior. Tais fatores, por vezes, podem representar um empecilho para um maior ingresso feminino na academia.

Segundo Casa Nova (2014), em 2012, dos 244 docentes dos programas de Contabilidade no Brasil, apenas 61 eram mulheres (25\%). Em estudo realizado anteriormente, Casa Nova (2012, p. 40), constatou que, na Faculdade de Economia, Administração e Contabilidade (FEA/USP), conforme dados de 2010, cerca de $16 \%$ apenas do corpo docente era representado por mulheres. A pesquisa de Santana, Nganga e Leal (2014), sobre o perfil e produção dos docentes dos cursos de mestrado e doutorado em Contabilidade, foi constatado que há predominância do gênero masculino $(83,63 \%)$. Com base na Plataforma Sucupira, nesta pesquisa observou-se que o corpo docente da pós-graduação stricto sensu da FEA/USP, em 2016, era composto de apenas $12 \%$ de mulheres.

Na pesquisa realizada, constou-se que, nos cursos de mestrado acadêmico, os ingressos do gênero feminino (44\%) ocorrerem em menores proporções do que do masculino (56\%). Também nos cursos de doutorado, os ingressos do gênero feminino (42\%) foram menores do que do masculino (58\%). Os resultados, principalmente os relacionados às proporções de ingressantes no mestrado, se aproximam com a quantidade de profissionais com registros ativos nos CRCs, que em 2016 era em média de 57\% (CFC, 2016).

O AICPA (2015), revelou que nos EUA, no período de 2013 a 2014, o gênero masculino apresentava um número de bacharelandos (54\%) e doutorandos (52\%) superior ao feminino. Nos cursos de mestrado, foi observado um número um pouco maior de estudantes femininos (53\%) do que masculinos (47\%). Os percentuais médios também se apresentaram distintos de acordo com as regiões para ambos os gêneros e para instituições públicas e privadas. Já a distribuição do gênero entre graduados e as tendências de matrículas, indicou mais licenciados masculinos (54\%) do que femininos; maior número do gênero feminino no nível de mestrado (51\%); e maior proporção de homens no nível $\mathrm{PhD}(64 \%)$.

No Brasil, quando observado por regiões, os matriculados nos cursos de mestrado acadêmico revelam, na região Nordeste, um percentual médio de $47 \%$ de ingressantes femininos; no Centro-Oeste, 46\%; e no Sudeste, em média, um total de $40 \%$ de mulheres. Isso denota um número maior de ingressantes masculinos nessas três regiões. Contrariamente, no Sul, observou-se um ingresso do gênero feminino (53\%), superior ao masculino (47\%) nos cursos de mestrado acadêmico. Os resultados de cada macrorregião não revelam proximidades com os dados do CFC (2016), o que sugere que há outros fatores regionais, culturais e institucionais que podem estar exercendo influências sobre estes percentuais. 
Em relação ao ingresso médio nos cursos de doutorado, as mulheres representaram no Nordeste cerca de 25\%; do total de ingressantes; no Centro-Oeste, 39\%; e no Sudeste e Sul, 43\%. Portanto, observa-se uma disparidade entre as regióes, no que concerne ao acesso das mulheres aos cursos de doutorado, com diferenças mais acentuadas na região Nordeste. Ressalta-se, no entanto, que esses programas são mais recentes, se comparados aos Programas das regiões Sudeste e Sul. Por sua vez, esses também apresentaram valores distintos quanto à acessibilidade feminina aos cursos de doutorado, sendo no Sudeste $40 \%$ para mestrado e $43 \%$ para doutorado; já no Sul, $53 \%$ para mestrado e $43 \%$ para doutorado.

Os números apresentados revelam que as matrículas femininas na região Sul já ultrapassam as masculinas nos cursos de mestrado. Isso não é realidade para todas as regiões brasileiras, necessitando maiores estudos a fim de encontrar fatores explicativos para as diferenças, inclusive para o fato disso não se manter nos cursos de doutorado nesta região.

Além de o estudo evidenciar que existe um predomínio do gênero masculino nos cursos de mestrado acadêmico e mestrado profissional e no doutorado, a pesquisa evidenciou que isso também ocorre dentro das instituições, pelas composições do corpo docente predominantemente masculinas (mais de 74\%), confirmando o que a literatura vinha retratando (Rothwell, 1985; Ott, 1989; Caplan \& Caplan, 1994; Husu, 2001; Buck et al., 2008; Haynes 2008; Bagilhole \& White, 2011; Haynes, 2017).

Esse cenário instiga questionamentos da seguinte natureza: Em que medida as diferenças evidenciadas podem representar as primeiras barreias enfrentadas pelas mulheres no ingresso da carreira docente? Quais os principais fatores que influenciam os níveis reduzidos de mulheres na docência em Ciências Contábeis? Existe uma expectativa de mudança nos próximos anos para que isso se reverta, com a renovação do quadro de professores em função de aposentadorias?

Haynes (2017) aduz que, embora se perceba uma melhora nos últimos 25 anos em termos numéricos da posição das mulheres na Contabilidade, ainda se mantem desafios em vários níveis. Rothwell (1985), destaca que elas ainda enfrentam um mercado predominantemente masculino. Pinto (2007), adverte que, mesmo que as mulheres venham tendo um crescente aumento de espaço na educação, ainda não se percebe na pós-graduação o fenômeno que vem ocorrendo na graduação, em que o gênero feminino predomina.

Diante desse contexto, destaca-se a necessidade de novas pesquisas e mais discussões sobre a igualdade de gênero em todos os ambientes laborais. Por recomendação de Morley e Crossouard (2015), o gênero deveria, inclusive, ser incorporado na política de educação superior. Desse modo, torna-se relevante que as universidades rastreiem estatísticas por gênero, com o intuito de promover a igualdade e a integração de gênero, acompanhadas de planos estratégicos de ação, recursos e mecanismos de acompanhamento ao longo do tempo.

\section{Conclusões}

Este estudo objetivou verificar a presença do gênero feminino entre os discentes nos programas de pós-graduação em Ciências Contábeis do Brasil, no período de 2010 a 2016. Os dados levantados revelaram que, na média do período pesquisado, houve predominância do gênero masculino, tanto no nível de mestrado como no de doutorado. Portanto, os dados indicam que a presença feminina nos programas de pós-graduação em Ciências Contábeis do Brasil tem sido inferior à masculina. Embora se perceba um aumento no ingresso das mulheres nos cursos de graduação em Ciências Contábeis, na pós-graduação stricto sensu ainda há predomínio do gênero masculino, principalmente nos cursos de doutorado.

Os resultados, em média, estão alinhados aos achados de Velloso e Velho (2001), de que existe igualdade entre os gêneros feminino e masculino no que se refere a presença no mestrado e em proporções semelhantes no doutorado. No estudo em si, esta diferença é pequena - cerca de $2 \%$ a menos de mulheres ingressantes nos cursos de doutorado (42\%), comparativamente aos cursos de mestrado acadêmico. Embora se percebam mudanças ao longo dos anos, isso ainda não provocou reflexos significativos no aumento da participação feminina nos cursos de pós-graduação stricto sensu da área contábil. 
No entanto, foram observadas proporções diferentes de ingressantes masculinos e femininos por ano e região, com destaque para a existência de uma maior diferença percentual de ingressantes femininos nos cursos de doutorado (Nordeste 22\%, Centro-Oeste 7\%, Sudeste -3\% e Sul 11\%), em comparação aos de mestrado. Analisando-se por macrorregiões, observou-se que em média somente os programas da região Sul apresentaram número de matriculados do gênero feminino superiores ao masculino. No entanto, isso não se repete em nível de doutorado. A região com maior percentual de participação masculina nos ingressos é a região Sudeste, tanto no mestrado acadêmico como no doutorado.

Conclui-se, com base nos resultados da pesquisa, que a presença do gênero feminino entre os discentes dos programas de pós-graduação em Ciências Contábeis no Brasil tem aumentado, mas ainda há um longo caminho a ser percorrido para alcançar a igualdade de gêneros, em âmbito nacional. Tal é especialmente relevante se for considerado que isso pode se refletir em posteriores oportunidades de trabalho, na carreira docente feminina e em menor desigualdade de gêneros nas universidades.

Os achados devem ser interpretados com cautela em função do acesso temporal e distintas datas de início das atividades dos programas de algumas instituições, sendo algumas, como no caso do Nordeste, mais recentes. Do mesmo modo, os dados foram levantados na Plataforma Sucupira e são restritos às características e aos procedimentos adotados pelos programas no processo de seleção dos discentes. Um maior detalhamento dos aspectos do processo de seleção poderia contribuir para a compreensão dos motivos que levaram a estas diferenças no número de discentes ingressantes por gênero no período investigado.

Recomenda-se que futuras pesquisas investiguem outros elementos que possam explicar as diferenças encontradas. Observa-se a necessidade de serem exploradas as disparidades de gênero que ocorrem entre as IES na área contábil, no Brasil, seja na composição do corpo docente e estrutura dos cursos ou na atratividade para futuros discentes e profissionais. Sugerem-se estudos mais profundos dos processos culturais e estruturas intrínsecas, informais e sutis, que produzem e reproduzem desigualdades. É possível que haja interferências de políticas internas, como relação orientadores-orientandos e preferências.

\section{Referências}

Alvez, B. M., \& Pitanguy, J. (1985). O que é feminismo (5. ed.). São Paulo: Brasiliense.

American Institute of Certified Public Accountants (AICPA). 2015. Trends: In the supply of accounting graduates and the demand for public accounting recruits. American Institute of CPAs. Reportado em 01 ago. 2017, de: https://www.aicpa.org/InterestAreas/AccountingEducation/NewsAndPublications/ DownloadableDocuments/2015-TrendsReport.pdf

Andrade, L. F. S., Macedo, A. S., \& Oliveira, M. L. S. (2014). A produção científica em gênero no Brasil: um panorama dos grupos de pesquisa de administração. Revista de Administração Mackenzie, 15(6, ed. espec.), pp. 48-75. DOI: http://dx.doi.org/10.1590/1678-69712014/administracao.v15n6p48-75

Andrade, L. F. S., Macedo, A. S., \& Oliveira, M. L. S. (2014). A produção científica em gênero no Brasil: um panorama dos grupos de pesquisa de administração [Edição Especial]. Revista de Administração Mackenzie, 15(6), pp. 48-75. http://dx.doi.org/10.1590/1678-69712014/administracao.v15n6p48-75

Araújo, M. F. D. (2005). Diferença e igualdade nas relações de gênero: revisitando o debate. Psicologia Clínica, 17(2), pp. 41-52. DOI: http://dx.doi.org/10.1590/S0103-56652005000200004

Backlund, F. (2017). A project perspective on doctoral studies - a student point of view. International Journal of Educational Management, 31(7), pp. 908-921. DOI: http://dx.doi.org/10.1108/IJEM-042016-0075

Bagilhole, B., \& White, K. (2011). Introduction: Building a Feminist Research Network. In: Bagilhole, B., \& White, K. (Orgs.). Gender, power and management: A cross cultural analysis of higher education. Basingstoke: Palgrave Macmillan. pp. 1-19. DOI: http://dx.doi.org/10.1057/9780230305953 
Borges, S. H. (2008). A importância do ensino de pós-graduação na formação de recursos humanos para o estudo da biodiversidade no Brasil: um estudo de caso na ornitologia. Biota Neotropica, 8(1), pp. 21-27. DOI: http://dx.doi.org/10.1590/S1676-06032008000100002

Brandão, A. A., \& Teixeira, M. P. (2003). Censo étnico-racial da Universidade Federal Fluminense e da Universidade Federal do Mato Grosso. Niteroi: EdUFF.

Buck, G. A, Clark, V. L. P, Leslie-Pelecky, D., Lu, Y., \& Cerda-Lizarraga, P. (2008). Examining the cognitive processes used by adolescent girls and women scientists in identifying science role models: a feminist approach. Science Education, 92(4), pp. 688-707. DOI: http://dx.doi.org/10.1002/sce.20257

Caplan, P. J., \& Caplan, J. N. (1994). Thinking critically about research on sex and gender. New York: Harper Collins.

Casa Nova, S. P. C. (2012). Impactos de mestrados especiais em Contabilidade na trajetória de seus egressos: um olhar especial para gênero. Revista de Contabilidade e Controladoria, 4(3), pp. 37-62. DOI: http://dx.doi.org/10.5380/rcc.v4i3.29952

Casa Nova, S. P. C. (2014). Contabilidade das mulheres na universidade brasileira: lucros, e perdas, ingresso e permanência. Tese de livre-docência, Faculdade de Economia, Administração e Contabilidade, Universidade de São Paulo, São Paulo, SP, Brasil.

Conselho Federal de Contabilidade (CFC). (2016). Profissionais e escritórios registrados e ativos existem no território nacional. Recuperado em 02 fevereiro, 2016, de http://www3.cfc.org.br/spw/crcs/ConsultaPorRegiao.aspx?Tipo $=0$

Coordenação de Aperfeiçoamento de Pessoal de Nível Superior (CAPES). (2004). Plano Nacional de Pós-Graduação 2005-2010. Brasília: MEC/CAPES. Recuperado em: 12 julho, 2017, de https://www. capes.gov.br/images/stories/download/editais/PNPG_2005_2010.pdf

Coordenação de Aperfeiçoamento de Pessoal de Nível Superior (CAPES). (2013). Resultados da avaliação da Capes revelam que pós-graduação teve crescimento de 23\% no triênio. Recuperado em 10 fevereiro, 2016, de http://www.capes.gov.br/36-noticias/6689-resultados-da-avaliacao-da-capes-revelam-que-pos-graduacao-teve-crescimento-de-23-no-trienio

Coordenação de Aperfeiçoamento de Pessoal de Nível Superior (CAPES). (2014). Plataforma Sucupira. Recuperado em: 12 julho, 2017, de: http://www.capes.gov.br/avaliacao/plataforma-sucupira

Cunha, J. V. A., Cornachione Jr., E. B., \& Martins, G. A. (2008). Pós-graduação: o curso de doutorado em ciências contábeis da FEA/USP. Revista Contabilidade \& Finanças, 19(48), pp. 6-26. DOI: http:// dx.doi.org/10.1590/S1519-70772008000300002

Drucker, P. F. (1999). Management challenges for the 21st century. New York, Harper.

Durso, S. O., Cunha, J. V. A., Neves, P. A, \& Teixeira, J. D. V. (2016). Fatores motivacionais para o mestrado acadêmico: Uma comparação entre alunos de Ciências Contábeis e Ciências Econômicas à luz da Teoria da Autodeterminação. Revista Contabilidade \& Finanças, 27(71), pp. 243-258. DOI: http:// dx.doi.org/10.1590/1808-057x201602080

Flynn, C. B, Feild, H. S., \& Bedeian, A. G. (2011). "Life could be a dream" What US-based management $\mathrm{PhD}$ students desire in an initial academic appointment? Career Development International,16(4), pp. 316-341. DOI: https://doi.org/10.1108/13620431111158760

Fogarty, J. T., \& Goldwater, M. P. (2010). Beyond just desserts: The gendered nature of the connection between effort and achievement for accounting students. Journal of Accounting Education, 28(1), pp. 1-12. DOI: http://dx.doi.org/10.1016/j.jaccedu.2010.09.001 
Franke, A., \& Arvidsson, B. (2011). 'Research supervisors' different ways of experiencing supervision of doctoral students. Studies in Higher Education, 36(1), pp. 7-19. DOI: http://dx.doi. org/10.1080/03075070903402151

Godinho, T., Ristoff, D., Fontes, A., Xavier, I. M., Sampaio, C. E. M. (2005). Trajetória da mulher na educação Brasileira. Brasília: INEP.

Gomes, A. F. (2005). O outro no trabalho: mulher e gestão. Revista de Gestão USP, 12(3), pp.1-9. DOI: http:// dx.doi.org/10.5700/issn.2177-8736.rege.2005.36522

Gomes, C. A. S, Corrêa, D. M. M. C, \& Domingos, S. R. M. (2010). Participação feminina na produção científica em contabilidade publicada nos Anais dos Eventos EnANPAD, Congresso USP de Controladoria e Contabilidade e Congresso ANPCONT. Anais Encontro da Associação Nacional de Pós-Graduação em Administração, Rio de Janeiro, RJ, Brasil, 34.

Granovetter, M. (1978). Threshold models of collective behavior. American Journal of Sociology, 83(6), pp. 1420-1443.

Haynes, K. (2008). Moving the gender agenda or stirring chicken's entrails? Where next for feminist methodologies in accounting? Accounting, Auditing \& Accountability Journal, 21(4), pp. 539-555. DOI: http://dx.doi.org/10.1108/09513570810872914

Haynes, K. (2017). Accounting as gendering and gendered: A review of 25 years of critical accounting research on gender. Critical Perspective on Accounting, 43, pp. 110-124. DOI: 10.1016/j. cpa.2016.06.004

Husu, L. (2001). On metaphors on the position of women in academia and science. NORA, Nordic Journal of Feminist and Gender Research, 9(3), pp. 172-181.

Jurkus, A. F., Park, J. C., \& Woodard, L. S. (2011). Women in top management and agency. Journal of Business Research, 64(2), pp. 180-186. DOI: http://dx.doi.org/10.1016/j.jbusres.2009.12.010

Louro, G. L. (1996). Nas redes do conceito de gênero. In: Lopes, M. J. M., Meyer, D. E., \& Waldow, V. R. (Orgs). Gênero e saúde. Porto Alegre: Artes Médicas.

Madalozzo, R. (2011). CEOs e composição do Conselho de Administração: a falta de identificação pode ser motivo para existência de teto de vidro para mulheres no Brasil? RAC. Revista de Administração Contemporânea, 15(1), pp. 126-137. DOI: http://dx.doi.org/10.1590/S1415-65552011000100008

Melo, H. P., Lastres, H. M. M., \& Marques, T. C. N. (2004). Gênero no sistema da Ciência, Tecnologia e Inovação no Brasil. Revista Gênero, 4(2), pp. 73-94. DOI: http://dx.doi.org/10.22409/rg.v4i2.247

Meyers-Levy, J., \& Loken, B. (2014). Revisiting gender differences: What we know and What lies ahead. Journal of Consumer Psychology, 25(1), pp.129-149. DOI: http://dx.doi.org/10.1016/j. jcps.2014.06.003

Morley, L., \& Crossouard, B. (2015) Gender in the neoliberalised global academy: the affective economy of women and leadership in South Asia. British Journal of Sociology of Education, 37(1), pp. 149168. DOI: http://dx.doi.org/10.1080/01425692.2015.1100529

Mota, E. R. C. F., \& Souza, M. A. (2013). A evolução da mulher na Contabilidade: os desafios da profissão. Anais do Congresso Convibra, São Paulo, SP, Brasil.

Nascimento, S., \& Beuren, I. M. (2011). Redes sociais na produção científica dos Programas de Pós-Graduação de Ciências Contábeis do Brasil. RAC Eletrônica, 15(1), pp. 47-66. DOI: http://dx.doi. org/10.1590/S1415-65552011000100004

Nascimento, V. M. S., \& Alves, F. J. (2014). Gênero e carreira: Um estudo de caso das percepções de Contadores Públicos. Anais Congresso USP de Controladoria de Contabilidade, São Paulo, São Paulo, SP, Brasil, 14. 
Pinto, G. (2007). Gênero, raça e pós-graduação: um estudo sobre a presença de mulheres negras nos cursos de mestrado da Universidade Federal Fluminense. Dissertação de Mestrado, Universidade Federal Fluminense, Niterói, RJ, Brasil.

Plataforma Sucupira. (2016). Coleta CAPES. Recuperado em: 12 julho, 2017, de https://sucupira.capes. gov.br/sucupira/

Ott, E.M. (1989). Effects of the male-female ratio at work: Police women and male nurses. Psychology of Women Quarterly, 13(1), pp.41-57. DOI: http://dx.doi.org/10.1111/j.1471-6402.1989.tb00984.x

Reina, D., Reina, D. R. M, Silva, H. A. S., \& Ensslin, S. R. (2012). Pós-Graduação em Contabilidade: Um estudo comparativo em cinco países. Gestão \& Regionalidade, 28(82), pp. 49-63. DOI: http://dx.doi. org/10.13037/gr.vol28n82.1399

Rothwell, S. (1985). Is management a masculine role? Management Education and Development, 16(2), pp. 79-98.

Saffioti, Saffiotti H. I. B. (1997). Violência de gênero: lugar da práxis na construção da subjetividade, $L u$ tas Sociais, 2(1), pp. 59-79.

Santana, A. R., Nganga, C. S. N., \& Leal, E. A. (2014). Perfil e produção científica dos docentes nos Cursos de Pós-Graduação Stricto Sensu em Ciências Contábeis. Anais do Congresso UFSC de Controladoria e Finanças e Iniciação Cientifica em Contabilidade, São Paulo, SP, Brasil, 14.

Scott, J. W. (1995). Gender: A usefull category of historical analysis. Educação \& Realidade. 20(2), pp. 71 99. DOI: http://dx.doi.org/10.2307/1864376

Silva, C. N., Anzilago, M., \& Lucas, A. C. (2015). A mulher contabilista nas publicações acadêmicas brasileiras. Anais Congresso USP de Contabilidade e Controladoria, São Paulo, SP, Brasil, 15.

Silva, S. M. C. (2016). Tetos de vitrais: gênero e raça na contabilidade no Brasil. Tese de Doutorado, Universidade de São Paulo, São Paulo, SP, Brasil.

Souza, M. A., Machado, D. G., \& Bianchi, M. (2011). Um perfil dos programas brasileiros de pós-graduação stricto sensu em Contabilidade. Revista de Educação e Pesquisa em Contabilidade, 5(2), pp. 6795. DOI: http://dx.doi.org/10.17524/repec.v5i2.344

Tabak, F. (2002). O laboratório de Pandora: estudos sobre a ciência no feminino. Rio de Janeiro: Gramond.

Tavares, H. M. F. (2000). Pesquisa brasileira precisa de um novo perfil. Revista Pesquisa Fapesp, n. 56. Recuperado em 02 fevereiro, 2016, de http://revistapesquisa.fapesp.br/

Tedeschi, L. A. (2007). Gênero: uma palavra para desconstruir e construir usos políticos. Revista Artemis, 6(1), pp. 106-113.

Tilly, L. A. (1994). Gênero, história das mulheres e História social. Cadernos Pagu, 2(3), pp. 29-62.

Unmüßig, B. (2007). Política de gênero faz a diferença: o futuro da política feminista e da democracia de gênero na Fundação Heinrich Böll. Berlim: Heinrich Böll Stiftung - A Fundação da Politica Verde. Recuperado em 13 Janeiro, 2016, de http://br.boell.org/downloads/Politica_de_genero_faz_a_diferenca_-_hbs_position_paper(2).pdf

Velloso, J., \& Velho, L. (2001). Mestrandos e doutorandos do país: trajetórias de formação. Brasilia: Capes. Recuperado em 10 julho, 2016, de http://www.dominiopublico.gov.br/pesquisa/DetalheObraForm. do?select_action $=\&$ co_obra $=24681$

Weyer, B. (2007). Twenty years later: explaining the persistence of the glass ceiling for women leaders. Women in Management Review, 22(6), pp. 482-496. DOI: http://dx.doi.org/10.1108/09649420710778718 